\title{
Benchmarking Systems and Methods for Environmental Performance Models
}

\author{
Zuzana Chvátalová ${ }^{1}$, Jiří Hřebíček ${ }^{2}$, and Oldřich Trenz ${ }^{2}$ \\ ${ }^{1}$ Brno University of Technology, Faculty of Business and Management, \\ Kolejní 4, 61200 Brno, Czech Republic \\ chvatalova@fbm. vutbr.cz \\ ${ }^{2}$ Mendel University, Faculty of Business and Economics, \\ Zemědělská 1, 61300 Brno, Czech Republic \\ \{jiri.hrebicek, oldrich.trenz\} @mendelu.cz
}

\begin{abstract}
Many business activities and procedures influence the environment. This environmental impact has to be assessed. We consider companies where the procedure of measuring environmental performance is applied through an environmental management system. The benchmark methodology has been developed precisely for these companies. This benchmark methodology can be used in the initial assessment as a screening method in sectors of different economic activities. The paper surveys the methodology that is designated for the environmental performance assessment of companies in the food-processing sector and introduces the architecture of the Web environmental benchmarking and reporting system that has been also developed.
\end{abstract}

Keywords: benchmark methodology, criteria, environmental performance, information system, environmental indicators, environmental performance evaluation, environmental reporting.

\section{Introduction}

Benchmarking is the process of improving performance by identifying, understanding, adapting and implementing best practices and processes that are found inside and outside a company. It involves the creation of partnerships to exchange information on processes and measurements, resulting in the setting of realistic improvement goals. Effective benchmarking is a process of continuous improvement [1].

Benchmarking is a framework within which performance indicators and the best practices are examined in order to determine areas where the company performance can be improved. Although most benchmarking initiatives concern financial and management issues, environmental benchmarking is becoming a major element in the environmental management of companies.

Environmental benchmarking is an environmental management tool that can provide a substantial contribution to the improvement of environmental performances by facilitating the identification of the gap between company performance and an optimal performance [3]. It helps the company's management to find out how to 
continuously and exactly monitor the development of the company's environmental impacts in the chosen sector (economic activities connected with NACE - Statistical classification of economic activities [6]) and to find relationships between the environment, the economy and society and to transform them into Key Performance Indicators (KPIs) [5], [7], [8] for the measurement of environmental performance.

What is benchmarked in environmental benchmarking? The scope of environmental benchmarking should include all areas of the given company's activities, and not be restricted solely to those activities that have an obvious environmental impact. Therefore, it may include an assessment of Environmental Management Systems (EMS), management performance, Environmental Management Accounting (EMA), resource and waste management, product environmental quality, environmental education and training, customer relations and emergency response [2].

Let us consider the environmental performance and the KPIs for the food processing sectors with NACE codes: C10 - Manufacture of food products and C11 Manufacture of beverages in the section 2 of the paper. Here we have taken into account the Global Reporting Initiative (GRI), its G4 Guidelines [9] and the Food processing guideline of G4 Sector Disclosures [10] and our past research [12] to specify the KPIs. We have also analyzed the Sustainability Assessment of Food and Agriculture systems (SAFA) [11] of the Food and Agriculture Organization of United Nations (FAO), its holistic global framework for the assessment of sustainability along the food and agriculture value chains, and this in order to optimize the environmental performance and the KPIs [14]. Furthermore, we consider benchmarking as an ongoing process of actions, steps, functions and activities that aims to identify and adopt best practices for improving environmental performance specified by a given company's KPIs. A number of different methods for benchmarking have been developed [15], [16]. We have considered the process based on EEA methodology [2] in the section 3 of the paper and we have applied this to chosen companies' food processing sector in the section 4 where we mention the architecture of the Web information system that has been developed as a part of our project [13].

\section{Key Performance Indicators of the Food Processing Sector}

The ISO 14031:2013 international standard [17] sets out Environmental Performance (EP) as measurable results of a company's management of its environmental aspects. The Environmental Performance Evaluation (EPE) is defined in ISO 14031:2013 as follows: A process to facilitate management decisions regarding a company's EP by selecting indicators, collecting and analysing data, assessing information about EP, reporting and communicating, and periodically reviewing and improving this process. Therefore, the EPE is a process which enables companies to measure, evaluate and communicate their EP using KPIs, based on reliable and verifiable information.

The ISO 14031:2013 standard describes two general categories of indicators for EPE: Environmental Performance Indicators (EPIs); and Environmental Condition Indicators (ECIs). There are two types of EPIs: 
1. Management performance indicators (MPIs) provide information about management efforts to influence the environmental performance of the company's operations.

2. Operational performance indicators (OPIs) provide information about the environmental performance of the company's operations.

The EPE process defined in ISO 14031:2013 and likewise in ISO 14031:1999 is too general including methods how to determine KPIs and choose appropriate EPIs and ECIs indicators. In addition, there are many international standards for implementing and certifying the sustainability pillars of environmental indicators, like for instance ISO 9000, ISO 14000, ISO 18000 [18]; ISO 26000 [19]; GRI [9], [10]; SAFA [11]; the Eco-Management and Audit Scheme [20] and the Organization for Economic Cooperation and Development (OECD) Guidelines for Multinational Enterprises [21].

We have been developing specified KPIs for the food processing sector [4], [5], [8], [12] since 2007. We introduce the results of our research of KPIs' determinants in the food processing sector $\mathrm{C} 10$ and $\mathrm{C} 11$ in Table 1, where we follow the trends which brought the frameworks of the GRI and SAFA principles with our conclusions [4], [12], [14], [22] and [23].

Table 1. List of KPI Indicators [23]

\begin{tabular}{|c|c|c|c|}
\hline Area & Indicator & Title & Unit \\
\hline \multirow{2}{*}{ Investment } & EN1 & Investments into environmental protection & Czech crown \\
\hline & EN2 & The cost of investment into environmental protection & Czech crown \\
\hline \multirow{2}{*}{ Emission } & EN3 & $\begin{array}{l}\text { Total air-emissions (at least } \mathrm{SO}_{2}, \mathrm{NO}_{\mathrm{x}}, \mathrm{CO}, \mathrm{VOC}, \mathrm{NH}_{3} \text { and } \\
\mathrm{PM}_{20,50,10} \text { ) }\end{array}$ & Ton \\
\hline & EN4 & $\begin{array}{l}\text { Total greenhouse gas emissions }\left(\mathrm{CO}_{2}, \mathrm{CH}_{4}, \mathrm{~N}_{2} \mathrm{O}, \mathrm{HFCs} \text {, }\right. \\
\left.\text { PFCs and } \mathrm{SF}_{6}\right)\end{array}$ & $\mathrm{kg}$ of $\mathrm{CO}_{2}$-eq \\
\hline \multirow{5}{*}{$\begin{array}{l}\text { Resource } \\
\text { consumption }\end{array}$} & EN5 & Total annual energy consumption & MWh \\
\hline & EN6 & Total consumption of renewable energy & $\%$ \\
\hline & EN7 & Material use (except water and energy) & Ton \\
\hline & EN8 & Recyclable input material use & $\%$ \\
\hline & EN9 & Total annual water consumption & $\mathrm{m}^{3}$ \\
\hline \multirow{2}{*}{ Waste } & EN10 & Total annual waste production & Ton \\
\hline & EN11 & Total annual production of hazardous waste & Ton \\
\hline
\end{tabular}

\section{Benchmarking Systems Methodology}

The benchmarking process is a series of actions, steps, functions, or activities that bring about an end or a result: the identification and importance of best practices for the improvement of EP. There are dozens of sources which describe the benchmarking process. It is called by some "the nine-step benchmarking process", or by others "the 
four steps of benchmarking". The following description of phases is based on Andersen and Pettersen [1], who call the process "the benchmarking wheel", in order to indicate that benchmarking is an ongoing process [23]:

1. Plan: During the planning phase, the scope and type of environmental benchmarking are determined. The focus here lies in process benchmarking, because, through the analysis of best practices, it provides a basis for substantial improvements. The planning stage involves: selecting what is to be benchmarked; analysing the organization processes; establishing performance measures for the process; selecting benchmarking partners that will participate in the benchmarking process; and determining the data collection methods that will be employed.

2. Search: A primary task is to search for and identify suitable benchmarking partners in the investigated sector. This includes the following activities: to design a list of criteria which an ideal benchmarking partner should satisfy (e.g., geographical location, size, structure, products, technology, economic activity, and organisational climate); to search for potential benchmarking partners (i.e., companies that are better than oneself at the process in question); to compare the candidates and select the best-suited benchmarking partner(s) (it is recommended to select more than one possible benchmarking partner); to establish contact with the selected partner(s) and gain their acceptance for participation in the benchmarking study. The companies of the food processing sector (NACE codes C10, C11) were selected on the basis of the database of the Czech Environmental Information Agency of the Ministry of the Environment of the Czech Republic, which have enabled and certified their EMS with the ISO 14001 or EMAS standards in 2007 [23].

3. Observe and Collect Data: The steps of the observation phase are as follows: to assess the information needs (data and information should be collected on EP levels, which indicate how good the partner is compared to oneself; practices or methods which make it possible to achieve these EP levels, and enablers who make it possible to perform the process according to these practices or methods); select the method and tool for collecting the information and data; observe and debrief (it is important that after the visit a debriefing is conducted as soon as possible in order not to lose any details of the observation). We have combined the collection of data through the abovementioned Web Information System and also through personal visits of the investigated company's responsible environmentalists [16]. The selected companies were further explored (we have used their annual reports, website, etc.) and submitted for evaluation according to additional criteria that were relevant to the selection of companies for our research [23].

4. Analyse: The descriptive statistics were made on the grounds that certain specifics of variables have an influence on the result of the methods and timing, and this can be seen in the descriptive statistics of the individual indicators. The average, standard deviation, variance and coefficient of variation were calculated. To determine the dominant factors which affect the company the method of the main components was used; the appropriateness of the data was tested using Bartlett's Test of Sphericity and the Kaiser-Meyer-Olkin Measure of Sampling Adequacy [23]. The main purpose of this phase is to determine: the EP gaps between benchmarking partners; the causes of the gaps, such as the methods and practices 
that make it possible for partners to achieve higher performance levels; the factors that facilitate or hinder the adoption of best practices and methods.

5. Adapt: The main findings of the analysis phase are communicated and discussed with the benchmarking partners. The best practices identified during the benchmarking were adapted and improved by the companies and recommendations were developed for their implementation [23].

6. Continuous Improvement: Benchmarking should not be a one-time event but an interactive, continuous and dynamic process for improving a company's EP. This involves monitoring the process, introducing continuous learning and providing input for the company's continuous improvement. It could be done by means of the Web information system that has been developed.

\subsection{Environmental Benchmarking Information Tools}

Some information and communication technology (ICT) tools are available for the purposes of environmental benchmarking. There exist both generic and specific ICT tools for environmental benchmarking [16]. We mention several of them here:

- e-Bench [24] is a Web-enabled audit and simulation/modelling tool that is used to record systematically whatever energy or utilities an organization is consuming and to relate these to the core business activity. The system then benchmarks these input factors to identify how efficiently they are used with other users in the database. e-Bench has been successfully used in the USA, Australia and New Zealand.

- The Global Environmental Management Initiative (GEMI) [25] is a coalition of large businesses aimed at providing strategies for businesses to achieve Environmental, Health and Safety (EHS) excellence, economic success, and corporate citizenship. The group introduced their primer for environmental benchmarking in 1994. The primer is not industry or sector-specific, and is accessible to everyone free of charge on the Internet. This ICT tool can be used as a framework for any kind of benchmarking, whether focusing on roles, strategic issues, processes or performance.

- The Safety, Health and Environment Intra Industry Benchmarking Association (SHEIIBA) [26] was formed in 1996 in response to the recognition that many leading companies were eager to learn how others in different sectors managed EHS and to compare their accident performance. Corporate Benchmarking Ltd. (in SHEIIBA) has built and runs bespoke safety benchmarking programmes for industry sectors. Participating companies enter accident and ill-health data into an online form each month. The data is divided by cause and type and can by split into different employee groups. Data can be viewed in graphic or tabular format as fixed periods, rolling years or time spans (up to 12 quarters or years.) The system is currently in use in 14 United Kingdom water utilities.

- Environmental Management Assessment and Benchmarking (EMAB) [27] is a Web application (portal) designed for the maturity assessment and benchmarking of corporate environmental management efforts [28]. The portal enables the measuring of corporate environmental management efforts via a survey that is based on criteria pursuant to the ISO 14000 family [17] and the EMAS III [20] standards. 
In addition to the assessment, there is a benchmarking function that allows the comparison with other participating companies. Its development started in 2009 at the Ostnabrück University as part of the project IT-for-Green [29] and has been going since spring 2014. The portal is in both German and English and is open especially for German companies.

Our analysis of known environmental benchmarking ICT tools together with the evaluation [16] show: an efficient ICT tool has to be based on reliable and purely scientific information of the main environmental impacts and aspects of companies of the given sector. Based on this the information environmental KPIs are worked out, and these are the foundations of a well-structured management benchmarking system. This system then has potential to be eco-efficient and easy to use [23].

\section{Web Information System}

We have applied the abovementioned ideas of section 3.1 to companies in the food processing sector of the Czech Republic, where we have identified the environmental performance model based on the specific conditions of the EMS implementation [16], [23] and we have furthermore developed a Web Information System for the environmental benchmarking of companies in this sector, where we have also used our experiences with the development of the Web Information System for the corporate performance and reporting [4], [14], [23], [30].

\subsection{System Requirements and Objectives}

In our vision, we foresee two main objectives of the developed Web Environmental Benchmarking and Reporting Information System (WEBRIS) [30]. A company may use such a system to create various reports and share its data with both its stakeholders and, in the future, with the state administrations concerned with regulatory demands and mandatory corporate reporting [23, p. 165-177].

The second objective of WEBRIS is the EPE performed by evaluating input KPIs (Tab. 1). This way, the company can share its EP with the public or check its EP development progress. EPE can be done through various reports as stated above or through custom dashboards [23, p. 223-228].

We define the following three main generic actors:

- Reporter - a person responsible for ensuring company mandatory environmental reporting (especially a company environmentalist) or reporting for stakeholders $[23$, p. 166]; this would typically be a member of the management team or a contractor..

- Evaluator - a person responsible for the EPE of a company [23, p. 212]; this role can be represented by a wide range of people starting from managers, auditors and various internal interested parties. The evaluator may also enter data into the information system, but it is not his/her primary task; typically, this would be the additional data required for the report generation, but not required as a part of mandatory reporting (e.g., company strategy, goals a targets, vision, etc.) 
- Administrator - the administrator of the information system responsible for defining the report templates and business rules used to generate reports [23, p. 212].

Basic high-level requirements for the Web information system are [23, 211-217], [30]:

- to store source company data; to evaluate KPIs according to the selected sector and methodology;

- to generate environmental benchmarking reports in the selected format for offline storage, printing and archiving;

- to import source company data from its company information system in the prescribed format;

- to provide selected information in the form of reports accessible online to the general public or only to selected persons;

- to provide selected information in the standardized XBRL (eXtensible Business Reporting Language) format for interchange with other systems [32];

- to provide the possibility to evaluate the company EP anonymously;

- to provide the possibility to define report data and business logic;

- to dynamically generate the XBRL taxonomies for a given report [32];

- to provide the possibility to customize standardized reports and to generate fully customized reports;

- to provide the possibility to compare reports among the companies of the given sector.

\subsection{WEBRIS Structure}

The Fig. 1 shows an overview of WEBRIS architecture based on an XBRL database. The main idea of this approach is a possibility of direct storing of XBRL data into an XML database that allows relational access to these data. The logical relational data model and the XBRL contents simplify the Business Intelligence integration [30, 31, 32]. The architecture of WEBRIS is divided into application, processing and data layers.

The application layer accepts report submissions and provides the results of report queries. It is composed of various interfaces such as a web application user interface or some defined APIs. The application layer communicates with the storage layer via SQL queries or via the XQuery language. It defines the access tools and internet protocols used for the following purposes: SOAP, REST, JDBC or file access via WebDAV.

The data layer is composed of both the RDB system and the XBRL database. The data layer exposes both the relational and the XML interface so that the data can be queried by both SQL and XQuery languages. The application layer provides a wide range of APIs to connect the database to various sources. This offers a high interoperability of the WEBRIS system. Alongside the application layer is the Business Intelligence engine [32], which can benefit from direct access to the data layer. This will be possible if the data layer is self-containing, i.e., if it can provide an XBRL document with all the necessary taxonomies and templates. 


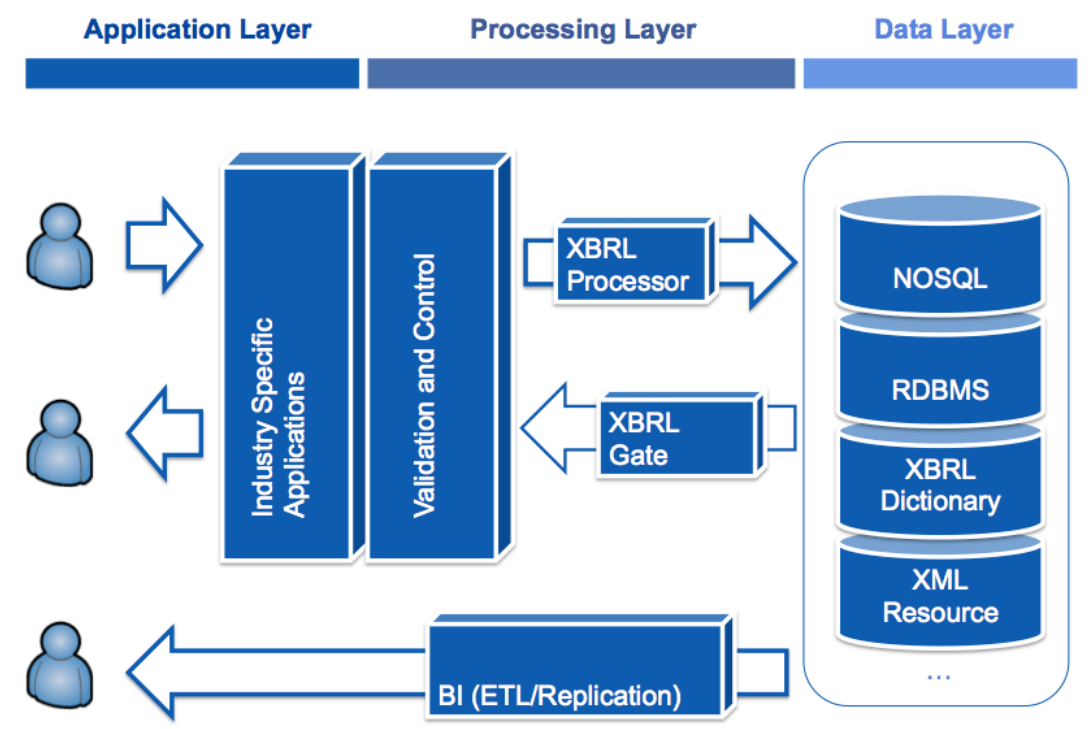

Fig. 1. WEBRIS architecture [30]

\subsection{WEBRIS Environmental Benchmarking Validation}

The pilot implementation of WEBRIS has been performed in the set of twenty four SME breweries in the Czech Republic which belong to C11 - Manufacture of beverages NACE section and which have determined their KPIs according to Tab. 1. The benchmark values were calculated firstly as the mean of the KPIs of the registered companies and after further analysis as the optimum value" consulted with environmental experts. The choice was made vis á vis the availability of comprehensive data from the given market segment and the willingness of companies to develop further. Another direction of the software implementation will be connected with improving the user-friendliness (in accord with feedback) and the integration of complementary methods for measuring company performance, together with an extension into other market segments.

Every user of WEBRIS, after completing the registration of his company, can input their KPIs (see Tab. 1) and thereupon the output benchmark will be determined. Based on the input KPIs, the benchmark will be shown. This means that the company EPE is performed based on the assessment of the KPIs that have been entered. The individual criteria are displayed in a ray chart (Fig. 2). The closer the partial value to the outer edge, the closer it is to the maximum evaluation level of the given segment (company benchmark). Emphasis in assessment is placed on sustainability. One part of benchmarking are recommendations useable for the further development of the company. 

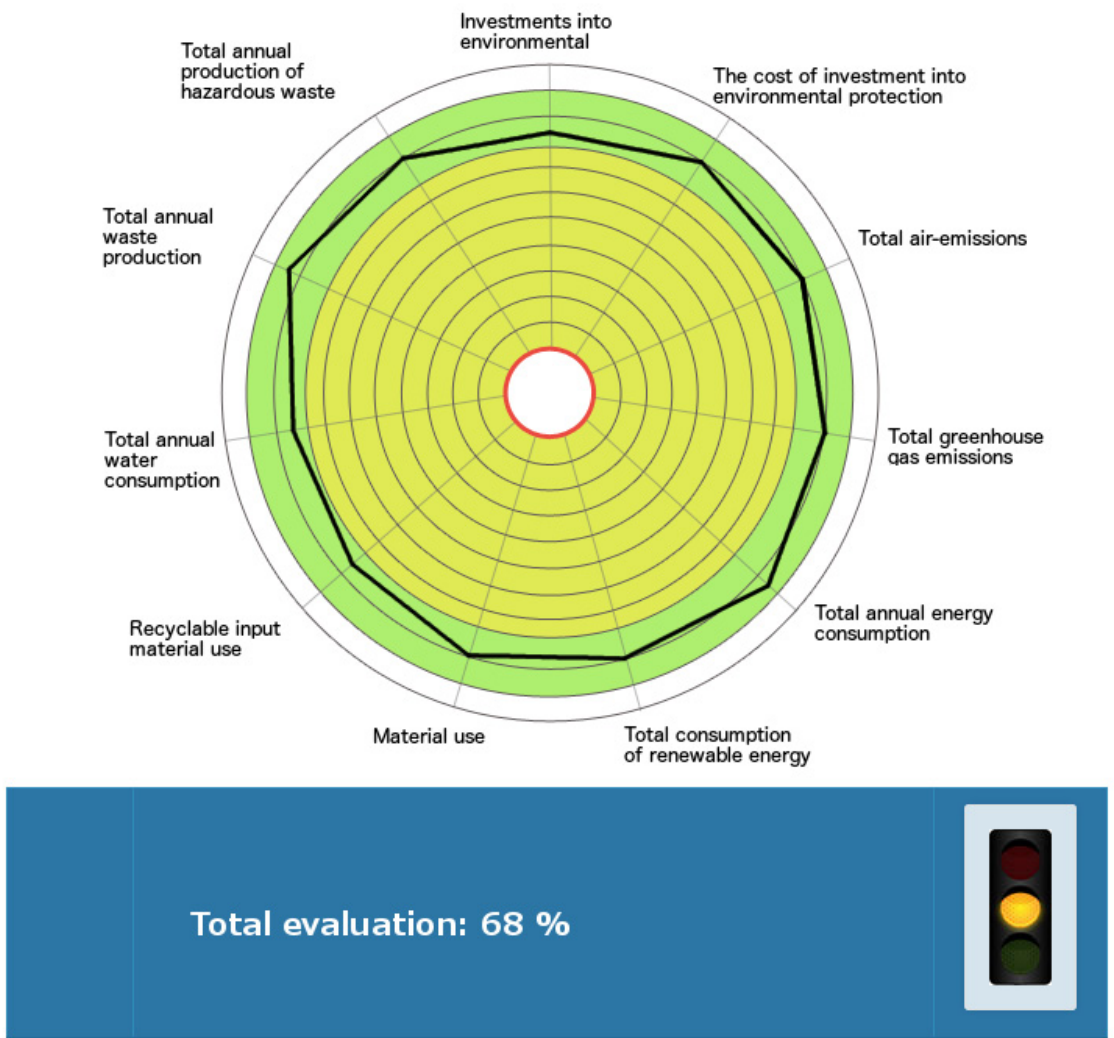

Fig. 2. Rating of the best company of the breweries that have been examined

\section{Conclusion}

Our research $[4,5],[8],[13,14],[23],[30,32]$ has focused the possibility of the utilization of ICT and XBRL taxonomy for environmental benchmarking and reporting of food processing organizations. We have suggested the formalization of this system on the basis of the universal XML markup language by means of the use of the XBRL $[30,32]$ and we have developed WEBRIS based on KPIs. We have assumed that it will minimize the main barriers that prevent the tested organizations $(\mathrm{C} 10$ and $\mathrm{C} 11$ NACE codes) from supporting environmental reporting. Some of their objections have been for example:

- Collecting and managing environmental data is expensive, technical issues with data collection are also a problem.

- Determining a set of appropriate KPIs to monitor and measure EP is difficult.

- Disclosure can create business risks which competitors and regulators may seize upon.

- Environmental reporting is seen as a superfluous and burdening activity.

The core of these barriers is the time-demanding nature of creating the breweries' data-processing reports, and the absence of positive feedback of their managers. 
By using WEBRIS, the given brewery gains a whole set of advantages. The administration and editing of KPIs is much easier and much more effective for EPE. The benchmark methodology in WEBRIS makes it possible to assess the given brewery's environmental impacts (caused by its activity) by means of objective considerations; to conduct the comparison of different breweries and evaluate whether their activities correspond to the principles of sustainable development.

Acknowledgments. The paper is supported by the Czech Science Foundation. Name of the Projects: "Measuring Corporate Sustainability Performance in Selected Sectors" Reg. No. 14-23079S.

\section{References}

1. Andersen, B., Pettersen, P.G.: The benchmaking handbook. Step-by-step instructions. Chapman \& Hall, London (1996)

2. Bolli, A., Emtairah, T.: Environmental benchmarking for local authorities:From concept to practice. EEA, Copenhagen (2001)

3. ECOSMES. Environmental benchmarking, http: / / www . ecosmes . net/ cm/navContents? l=EN\&navID=envBenchmar king\&subNavID $=1 \&$ pag $I D=1$

4. Hřebíček, J., Soukopová, J., Štencl, M., Trenz, O.: Corporate Key Performance Indicators for Environmental Management and Reporting. Actauniv. Agric. etsilvic. Mendel. Brun. 59, 99-108 (2011)

5. Hřebíček, J., Pekárková, L.: Key Performance Indicators for Sustainable Reporting According toNACE. In: Möller, A., Schreiber, M. (eds.) 22nd International Conference on Informatics fo Environmental Protection, Enviroinfo 2008. Environmental Informatics and Industry Ecology, pp. 45-53. Shaker Verlag, Aachen (2008)

6. List of NACE codes, http://ec.europa.eu/competition/mergers/ cases/index/nace_all.html

7. Hermann, B.G., Kroeze, C., Jawjit, W.: Assessing environmental performance by combining life cycle assessment, multi-criteria analysis and environmental performance indicators. Journal of Cleaner Production 15, 1787-1796 (2007)

8. Hřebíček, J., Mísařová, P., Hyršlová, J.: Environmental Key Performance Indicators and Corporate Reporting. In: International Conference EA-SDI 2007. Environmental Accounting and Sustainable Development Indicators, pp. 147-155. University Jana EvangelistyPurkyně, Ústí (2007)

9. G4 Sustainability Reporting Guidelines, https : / / www.globalreporting.org/reporting/g4/

10. G4 Sector Disclosures. Food processing, https: / /www.globalreporting.org/resourcelibrary/ GRI-G4-Food-Processing-Sector-Disclosures.pdf

11. SAFA, Sustainability Assessment of Food and Agriculture systems (SAFA) (2013), http: //www. fao.org/nr/sustainability/ sustainability-assessments-safa/en/

12. Hřebíček, J., Valtinyová, S., Křen, J., Hodinka, M., Trenz, O., Marada, P.: Sustainability Indicators: Development and Application for the Agriculture Sector. In: Erechtchoukova, M.G., Khaiter, P.A., Golinska, P. (eds.) Sustainability Appraisal: Quantitative Methods and Mathematical Techniques for Environmental Performance Evaluation, pp. 63-102. Springer, Heidelberg (2013) 
13. Measuring Corporate Sustainability in Selected Sectors. Project GACR GA14/23079S, http://gacr.pefka.mendelu.cz/en/index.php

14. Hřebíček, J., Soukopová, J., Trenz, O.: Current Trends of Economic Modelling of Sustainable Corporate Performance and Reporting - Review and Research Agenda. In: Nerudová, D. (ed.) Procedia Economics and Finance, vol. 12, pp. 234-242 (2014)

15. Hee-jeong, Y., Kun-mo, L.: Environmental Benchmarking Methodology for Identification of Key Environmental Aspects of Product. In: IEEE International Symposium onElectronics \& the Environment, pp. 21-26. IEEE Press, New York (2002)

16. Jónsdóttir, H., Sparf, A.M., Hanssen, O.J.: Enviromental Benchmarking a Tool for Continuous Environmental Improvements in the SME Sector. Nordic Innovation Centre, Oslo (2005)

17. EN ISO 14031: 2013. Environmental Management - Environmental Performance Evaluation - Guidelines (2013)

18. Integrated Management System Documentation / Manuals for Integrated Certification, http://www.isohelpline.com/ims_iso_9000_iso_14000_ohsas_1800 0_docu-ment_manual.htm

19. ISO 26000:2010. Social responsibility, http: / /www. iso. org/iso/iso26000

20. EMAS, http://ec.europa.eu/environment/emas/index_en.htm

21. OECD Guidelines for Multinational Enterprises,

http: / /www. oecd.org/document/28/

0,3746, en_2649_34889_2397532_1_1_1_1,00.html

22. Hřebíček, J., Trenz, O., Vernerová, E.: Optimal set of agri-environmental indicators for the agricultural sector of Czech Republic. Agric. etsilvic. Mendel. Brun. 61, 2171-2181 (2013)

23. Kocmanová, A., Hřebíček, J., Dočekalová, M., Hodinka, M., Hor-Nungová, J., Chvátalová, Z., Kubálek, T., Popelka, O., Šimberová, I., Topolová, I., Trenz, O.: Corporate performance measurement, Littera, Brno (2013) (in Czech)

24. e-Bench, http://www.e-bench.com/eBench/index.jsp

25. GEMI - Global Environmental Management Initiative, http: / / www .gemi .org/GEMIHome.aspx

26. SHEIIBA - Safety, Health and Environmental Intra Industry Benchmarking Service, http: / /www. sheiiba.com/

27. EMAB - Environmental Management Assessment and Benchmarking, http: / / www. emab. ertemis.eu/contao/homepage.html

28. Frehe, V., Stiel, F., Teuteberg, F.: A Maturity Model and Web Application forEnvironmental Management Benchmarking. AMCIS 2014, 1-14 (2014),

http: //aisel.aisnet.org/amcis2014/GreenIS/

GeneralPresentations/1/

29. IT-for-Green -, http: / / it-for-green.eu/

30. Hodinka, M., Štencl, M., Hřebíček, J., Trenz, O.: Business Intelligence in Environmental Reporting Powered by XBRL. Acta Univ. Agric. Silvic. MendelianaeBrun. 62, 355-362 (2014)

31. XBRL, https://www. xbrl.org/

32. Hodinka, M.: Formalization of Business Rules and Methodology of their Implementation to the Information System. Ph.D. thesis. Mendel University, Brno (2013)

33. Popelka, O., Hodinka, M., Hřebíček, J., Trenz, O.: Information System for Corporate Performance Assessment and Reporting. In: Long, C.A., Mastorakis, N.E., Mladenov, V. (eds.) 2013 International Conference on Systems, Control, Signal Processing and Informatics (SCSI 2013), pp. 247-253. EUROPMENT Press, New York (2013) 